\title{
PATTERN OF REFRACTIVE ANOMALIES IN WARRI METROPOLIS, DELTA STATE OF NIGERIA
}

\author{
BY \\ *KIO, F. E. AND OSTIA-EMINA, M \\ DEPARTMENT OF OPTOMETRY, UNIVERSITY OF BENIN, \\ BENIN-CITY, NIGERIA. \\ *Corresponding author
}

\begin{abstract}
A cross-sectional prevalent study of refractive errors conducted in Warri, a metropolitan town in delta state of Nigeria revealed peculiar prevalent rates. One thousand and eighteen eyes of 6 to 64 year olds were screened for refractive anomalies and 752 (73.9\%) eyes (369 male and 383 female eyes) were found with refractive errors. The distribution showed that $141(38.2 \%)$ female eyes and $141(36.8 \%)$ female eyes were myopic and $242(63.2 \%)$ female eyes and $228(61.8 \%)$ male eyes were hyperopic. Hyperopic was found to increase with age in both sexes. While myopia increased with age initially but decreased later at older age groups. Hyperopia and myopia were statistically not independent of age $(\mathrm{P}>0.01)$. Presbyopia was observed in $271(36.0 \%)$ eyes out of which $173(63.8 \%)$ were male eyes and $98(36.2 \%)$ female eyes. Of the presbyopic eyes, $35(20.2 \%)$ were found in the age group 25-34 years comprising 14 female and 21 male eyes. About $75 \%$ of those with refractive errors fell within $\pm 0.25 \mathrm{D}$ to $\pm 1.00 \mathrm{D}$ error range. The prevalence of error found in this study, indicates the need to upgrade the visual health services offered in Warri, in order to cope with higher demands expected from WHO vision 2020 programme.
\end{abstract}

KEYWORDS: Refractive errors, Presbyopia, Vision 2020, Emmetropisation,

\section{INTRODUCTION}

The study on prevalence of ametropia began with steiger who measured refractive power of the cornea in 5,000 children ${ }^{1}$. He observed that interactions of corneal power with calculated axial length of the eye, both of which are independent variables could cause all refractive error. The variable refractive medium of the eye is the crystalline lens which is an elastic structure situated in the anterior portion of the eye behind the iris. The ability of the lens to change shape helps to bring into focus objects at varying distances from the eye. The combined functions of the structures enable the eye to focus the image of an object on the fovea without which the object appears blurred. These form the basis of refractive error ${ }^{2}$.

Little is truly known about the actual cause of ametropia. Many suggestions have been given such as the biological view which states that a moderate amount of ametropia is a normal variant caused by environmental and genetic factors in man. To account for the large number of people with high refractive error, $\mathrm{Straub}^{3}$ postulated the theory of emmetropisation. This means that nature is incapable of producing only perfect eyes, and that there is a correlation in associating the optical components of the eye by nature. Therefore, emmetropisation is the coordination of mechanisms which fit the optical parts of the eye together. Emmetropisation mechanism may be said to have continued even after the eye stopped growing by its progressive flattening of the lens. This accounts for some reversal of myopia in older people ${ }^{4}$.

Children are usually hyperopic at birth and on completion of development become emmetropic. It may result in myopia. However, many remain hyperopic throughout life. Randall ${ }^{5}$ reported increase in hyperopia during school age and then decrease through puberty. This agrees with the later study done by Hirsh ${ }^{6}$. Jaeger ${ }^{7}$ observed marked increase in myopia at age 12 , which decreased at about the ages of 13 to 15 years. Staflova ${ }^{8}$ had similar result in Russian children from age 6 to 14 . It is significant to note that not all types of refractive errors are progressive. Myopia shows greater increase during the first two decades but the curve tends to flatten out at the end of the growth age. Bucklers ${ }^{9}$ reported that the earlier and higher the error manifested, the greater the tendency toward a quick and steady increase of myopia. Baldwin ${ }^{10}$ summed up that myopia develops and increases critically from 7 to 18 years.

Rasmussen ${ }^{11}$ studies showed that most children were hyperopic and adults more nearly emmetropic because of increased incidence of 
myopia with age. He observed that astigmatism and hyperopia were found in patients over 60 years. It was also observed that males developed myopia later in life than females and that the urban dwellers had higher incidence of myopia. This assertion was confirmed by Stenstron ${ }^{12}$ and Sorsby, et $\mathrm{al}^{13}$ through actual measurement of the various optical components of the eye.

The incidence and prevalence of refractive anomalies vary with age, race and environmental conditions. They also vary with medical and surgical anomalies and the population group studied. No single study can meet all criteria and no conclusion applies to all people ${ }^{14}$. Dearth of refractive data in Nigeria makes it important to evaluate the pattern of distribution of various refractive anomalies in Warri. This will give some insight into the visual needs of the population in Warri and provide baseline data for refractive error component of vision 2020 programme in Nigeria.

\section{MATERIALS AND METHOD}

Warri, an oil producing area of Nigeria, located in the delta region of the river Nigeria at latitude $5.65^{\circ} \mathrm{N}$ and longitude $5.50^{\circ} \mathrm{E}$. This city is situated close to the swampy forest area of Delta State. The population is cosmopolitan in outlook consisting of businessmen, petty traders and workers in the petroleum industries. Five hundred and nine subjects comprising 263 male and 246 female with an average age of 28 years were examined in this study. All the subjects were volunteers who showed up in response to advertisements for free eye examination.

They were screened for refractive error at locations within the communities. Visual acuity and subjective refraction were performed under shades provided by trees and open community holds and reflections from sunlight provided standard illumination and the required letter contrast. Snellen's illiterate 'E' chart was used for visual acuity measurement on all subjects whether literate or illiterate at 6 metres. Reduced illiterate 'E' chart was also used to measure the near point acuity at 0.4 metres. For the purposes of the screening, a visual acuity of $6 / 6$ was accepted as the standard at 6 meters and $\mathrm{N} 5$ types at 0.4 meters.

Those subjects with less than $6 / 6$ visual acuity had thorough refraction done on them to ascertain their actual refractive status. Trial lenses, frame and accessories, handheld occluder, retinoscope and meter rule were employed for effective screening. The subjects were tested with battery of trial lenses in \pm 0.25 diopter steps placed on the trial frame with subjective endpoints and final spectacle prescriptions determined to the subjects' best visual acuities. For the purpose of analyses, observed astigmatism was transposed to their spherical equivalents. Presbyopic subjects were also refracted and reported.

\section{RESULTS}

Table 1 shows that 1,018 eyes were examined for refractive errors out of which 752 (73.9\%) had errors, with 369 belonging to males and 383 belonging to females. Among the eyes with refractive errors, $282(37.5 \%)$ were myopic while $470(62.5 \%)$ were hyperopic. The rate of refractive errors in females was only slightly higher with $50.9 \%$ as compared to that of males with $49.1 \%$ while the males recorded their highest rate at age group between 55-64 years with $63.2 \%$, the females recorded their highest rate at the age group 55-64 years with $63.2 \%$, the females recorded their highest rate at the group 6-14 years with63.6\% (fig. la).

The converse is the case with lowest rates. The females recorded their lowest rate at the age group between 55-64 years with 36.8\% while males recorded their lowest rate at the age group between 6-14 years with $36.4 \%$. The trend observed is a gradual increase in the rate of refractive errors from the age group 6-14 years, peaking at the age group 55-64 years in males. While it peaked at the age group 6-14 years in females, it decreased gradually to the lowest at the age group 55-64 years. Overall male/female prevalence was 362.5 and 376.2 per 1,000 of the sampled population respectively but the prevalence was highest in the age group 15-24 years (table 2). Figs. la and Ib showed that the bulk of the refractive errors were observed in the age groups between 15 and 54years (prevalence range of 113.0 to 228.9 per 1,000 ), with age groups 6-14 years and 55-64 years recording much lower prevalence of 64.88 and 56.0 per 1,000 respectively.

A refractive error range of \pm 0.25 to $\pm 1.00 \mathrm{D}$ was observed in $74.5 \%$ of the eyes with errors, $\pm 1.25 \mathrm{D}$ to $\pm 2.00 \mathrm{D}$ in $15.2 \%$ and $\pm 2.25 \mathrm{D}$ to $3.00 \mathrm{D}$ in $4.4 \%$ of the eye with errors (fig. 2a). This means that only about $6 \%$ of them fell within $\pm 3.25 \mathrm{D}$ and $\pm 10.00 \mathrm{D}$ error range. The same observation could be made within the various age groups. In the age group 6-14 years, $86.4 \%$ of the eyes with refractive errors fell within \pm 0.25 and $+1.00 \mathrm{D}$ and $7.6 \%$ fell 
within $\pm 1.25 \mathrm{D}$ and $\pm 2.00 \mathrm{D}$ error range. In the age group 25-34 years, $71.3 \%$ of the eyes with refractive error fell with \pm 0.25 and $\pm 1.00 \mathrm{D}$ and $14.0 \%$ fell within $\pm 1.25 \mathrm{D}$ and $\pm 2.00 \mathrm{D}$ error range while in the age group $45-54$ years, $74.4 \%$ of the eyes with refractive errors fell within \pm 0.25 and $\pm 1.00 \mathrm{D}$ and $20.5 \%$ fell within $\pm 1.25 \mathrm{D}$ and $\pm 2.00 \mathrm{D}$ error range. Only within the $\pm 0.25 \mathrm{D}$ and $\pm 1.00 \mathrm{D}$ error range did female dominate the males $(52.9 \%$ females; $47 \%$ males) but the domination was largely influenced by the proportions within the 634 years age range. Fig. $2 \mathrm{~b}$ shows the trend of refractive errors across age groups. There is a shift in the peak distribution at the 6-14 years age group from emmetropia towards hyperopia. The peaks at all the other age groups fell within $0.25-1.00 \mathrm{D}$ of hyperopia.

Myopia was found in $282(37.5 \%)$ of the refracted eyes with a prevalence of 277 per 1,000 of the total sample (tables $1 \& 2$ ). These were equally distributed between both sexes. Prevalence rates in myopia are almost comparable with those of total refractive errors, the highest occurring at 15-24 years age group and tapering to the lowest at 55-64 years age group. Generally, the rate of myopia per age group increased between 6-24 years age groups, remained almost uniform between 25-44 years age group and gradually declining to the lowest at 55-64 years (fig. 3a \& $3 b)$. the trends in male-female distribution observed in the total refractive errors were also observed in myopia. The lowest rate for males occurred at age group between 6-14 years with $27.3 \%$ increasing gradually to highest $(88.9 \%)$ at age group between 55-64 years, while the females recorded their highest rate at the age group 6-14 years with $72.7 \%$ decreasing gradually to lowest $(11.1 \%)$ at age group between 55-64 years. Majority of the myopic eyes (57.5\%) fell within an error range of $0.25-1.00 \mathrm{D}, 20.9 \%$ within 1.25 $2.00 \mathrm{D}$ error range and $9.6 \%$ within $2.25-3,00 \mathrm{D}$ error range, while $12.0 \%$ myopic eyes fell between 3.25-10.00D error rangers. Similar observation could be within the age groups. In the $0.25-100 \mathrm{D}$ myopia range, the female eyes dominated within age groups 6-24 years while the male eyes dominated within age groups $25-54$ years. No eye in the group 55-64 years fell within this myopia range.

Hyperopia accounted for $470(62.5 \%)$ of the refracted eye with a total prevalence of 462.7 per 1,000 of the total sample (tables $1 \& 2$ ). Females were slightly more hyperopic than the males. The rates were not quite regular between age groups and between sexes, the irregularity was more pronounced in males but fig. 4a showed that the rates in total hyperopia increased from age group 614 years $(21.5 \%)$ to peak at 55-64 years $(67.6 \%)$. Between the age groups, the rates of hyperopia were higher within the 35-64years age groups. Age groups 15-24 and 45-64 years dominated the male hyperopes with $23.2 \%$ and $23.75 \%$ respectively. In the female hyperopes, only the age group 15-24 years dominated (fig. 4b). Majority of the hyperopic eyes $(84.7 \%$ ) also fell within $0.25-100 \mathrm{D}$ error range, $11.7 \%$ within $1.25-2.00 \mathrm{D}$ error range and $1.3 \%$ within $3.25-10.00 \mathrm{D}$ error ranges. only $2.3 \%$ fell within 3.25-10.00D error ranges. Patterns similar to myopia could be observed within each error range. While $53.3 \%$ of $0.25-1.00 \mathrm{D}$ hyperopic eyes were those of females, $46.7 \%$ were those of males. Within the same error range, female eyes dominated the 6-34 years age groups while male eyes dominated the 35-64 years age groups. Males and females demonstrated comparative prevalent rates within 1.25-2.00D hyperopic range (fig. 3).

Included in hyperopic errors are 5 eyes which were aphakic. Aphakia, therefore, accounted for $1.1 \%$ of the hyperopic eyes and $0.7 \%$ of all eyes with refractive error. One of the eyes belonged to a female in the 35-44 years age group and the remaining 4 were shared equally between the two sexes in the 55-64 years age group. All the aphakic eyes fell within +9.25 to +10 .00D error ranges.

Presbyopia was observed in 271 (26.6\%) eyes of which $173(63.8 \%)$ were from male eyes and 98 $(36.2 \%)$ from female eyes (table 3). Presbyopia occurred in the age groups between 25 and 64 years with a total prevalence of 266.2 per 1,000 eyes. At the earliest manifestation male eyes $(60.0 \%)$ were more than female eyes $(40.0 \%)$. The rate remained relatively progressive between the ages of 25 and 54 years but decreased slightly at the 55-64 years. The age group 25 to 34 showed presbyopic ADDs between +0.75D and +1.25D. An ADD of +3.00D was only observed in $5.9 \%$ of the presbypopic population. Overall, $36(13.3 \%)$ of the presbyopic eyes were able to read the N5 letter types with +1.00D ADD, $191(70.5 \%)$ eyes read the letters with ADDs within the range of +1.25 and $+2.00 \mathrm{D}$ ADD and $44(16.2 \%)$ eyes read the same letters with +2.25 to +3.00D ADD.

\section{DISCUSSION}

The purpose of this study is to generate data on the prevalence pattern of refractive errors amongst 
the inhabitant $\mathrm{s}$ of Warri, one of the areas harbouring the oil wealth of the country. Such data are necessary for the implementation of Vision 2020 progamme and other eye care services in the area. The results obtained so far compared favourably with the reports of Randall ${ }^{5}$ and Hirsh ${ }^{6}$ that predicted higher proportion of hyperopia at school age, which decreases through puberty and Rasmussen's study ${ }^{11}$ which suggested higher proportion of myopia later in life for male eyes than female eyes. Indeed in this study, higher proportion of hyperopia was observed at school age and both myopia and hyperopia were higher in males than females in the older age groups (figs. $3 b \& 4 b$ ). However, the theory of emmetropisation postulated by Straub and advocated by Hirsh and Baldwin which suggested a progression of such population to wards myopia as from the age of 7 years with the myopia increasing substantially up to the age of 18 years when a decline should begin to occur, did not quite conform with the findings in this study ${ }^{3610}$. The prevalence of myopia found between 7 and 18 years of age was just $27.7 \%$ as compared to hyperopia (46.2\%) and emmetropia (26.1\%). Though this agreed with the report of Walton $^{15}$ in which $23 \%$ myopia and $57 \%$ hyperopia were found in the sampled population in USA, beyond the age of 18 , hyperopia continued to increase while myopia either remained almost uniform or reduced. In the final analysis, inadequate sample and environmental influence are some explanations that could be adduced for the peculiar finding in this study.

As indicated earlier, this study is a crosssectional study in which the subjects used were volunteers that responded to an advertisement for free eye test. This makes the sample an incidental non probability sample and those that showed up were likely to be those who already developed visual symptoms and those who felt the need to undergo an eye test. Those likely to develop visual symptoms are hyperopes and low-grade myopes. This could therefore bias the population sample and influence the result greatly. As also suggested by the theory of emmetropisation, high academic achievement and persistent near work activities are responsible for the development or progression towards myopia. Since the screenings were carried out during the day time which coincides with office hours, it is also possible that the subjects who showed up for eye test were mainly the job seekers, petty traders and self-employed workers who could afford to take time off work to take advantage of a free eye test. These groups of people consist mostly of subjects not engaged in near work or meaningful academic programme and therefore not capable of developing myopia. The presbyopia observed as early as the 25-34 years age group in this study also confirms an abundance of uncorrected latent hyperopia at early adulthood. Furthermore environmental influences could play a major role in the development of ocular anomalies. In conformity with the theory that urban dwellers are likely to develop more myopia than rural dwellers, Warri as an urban area was expected to harbour inhabitants who engage more in activities which favour the development of myopia. However, the diversified activities in business and in the oil industry could not be said to favour the development of either myopia or hyperopia. While office activities favour the development of myopia, field activities favour the development of hyperopia. Since more hyperopia is the case only a prevalence study, which makes use of a well randomised sample, which include a documentation of the occupations of the subjects used would either confirm or reject the findings in this study.

An attempt at generating background data on the refractive needs of the population in Warri for possible strategic planning of visual health services and establishment of primary eye care programme under the WHO vision 2020 initiative has yielded varied results that need confirmation through a well randomized prevalent study. However, the high prevalence of uncorrected refractive anomalies found in this study indicates an urgent need for upgrading the existing services in the area.

Presently in Warri, ocular and visual health services are provided by a General Hospital, two oil company clinics, private optometry clinics and private ophthalmology clinics. The services provided by all combined are grossly inadequate for the level of refractive anomalies found in the area. The services should be such geared towards providing periodic eye examination and visual correction in order to maximize visual health, function and efficiency and on the long run prevent progressive refractive anomalies that are prone to blindness. Furthermore, occupational visual assessment, protection and rehabilitation services are recommended particularly for those involved in hazardous visual tasks peculiar to the oil industries and other activities in Warri. 
TABLE 1: DISTRIBUTION OF REFRACTIVE ERRORS IN WARRI

\begin{tabular}{|c|c|c|c|c|c|c|c|c|c|c|c|c|}
\hline $\begin{array}{l}\text { AGE } \\
\text { GROUP } \\
\text { (YRS) }\end{array}$ & POP & ULA' & IION SAMPLE & \multicolumn{3}{|c|}{$\begin{array}{l}\text { NUMBER OF EYES WITH } \\
\text { REFRACTIVE ERROR }\end{array}$} & \multicolumn{3}{|c|}{$\begin{array}{l}\text { NUMBER OF EYES } \\
\text { WITH MYOPIA }\end{array}$} & \multicolumn{3}{|c|}{$\begin{array}{l}\text { NUMBER OF EYES } \\
\text { WITH HYPEROPIA }\end{array}$} \\
\hline $6-14$ & 102 & 103 & 205 & 24 & 42 & 66 & 6 & 16 & 22 & 18 & 26 & 44 \\
\hline $15-24$ & 127 & 158 & 285 & 95 & 138 & 233 & 42 & 60 & 102 & 53 & 78 & 131 \\
\hline $25-34$ & 95 & 100 & 195 & 75 & 89 & 164 & 38 & 35 & 73 & 37 & 54 & 91 \\
\hline $35-44$ & 75 & 43 & 118 & 68 & 47 & 115 & 30 & 15 & 45 & 38 & 32 & 70 \\
\hline $45-54$ & 90 & 54 & 144 & 71 & 46 & 117 & 17 & 14 & 31 & 54 & 32 & 86 \\
\hline $55-64$ & 38 & 33 & 71 & 36 & 21 & 57 & 8 & 1 & 9 & 28 & 20 & 48 \\
\hline Total & 527 & 491 & 1018 & 369 & 383 & 752 & 141 & 14 & 282 & 228 & 24 & 470 \\
\hline
\end{tabular}

TABLE 2: REVALENCE RATES OF REFRACTIVE ERRORS IN WARRI

\begin{tabular}{|c|c|c|c|c|c|c|c|c|}
\hline \multirow[t]{2}{*}{$\begin{array}{l}\text { AGE GROUP } \\
\text { (YRS) }\end{array}$} & \multicolumn{2}{|c|}{$\begin{array}{l}\text { PREVALENCE/1.000 OF } \\
\text { REFRACTIVE ERRORS }\end{array}$} & \multicolumn{3}{|c|}{$\begin{array}{l}\text { PREVALENCE/1,000 } \\
\text { OF MYOPIA }\end{array}$} & \multicolumn{3}{|c|}{$\begin{array}{l}\text { PREVA LENCE/1,000 } \\
\text { OF HYPEROPIA }\end{array}$} \\
\hline & M $\quad$ F & TOTAL & M & $\mathbf{F}$ & TOTAL & M & $\mathbf{F}$ & TOTAL \\
\hline 6- 14 & 23.6 & 64.8 & 5.9 & 15.7 & 21.6 & 17.7 & 25.5 & 43.2 \\
\hline $5-24$ & 135.6 & 228.9 & 41.3 & 58.9 & 100.2 & 52.1 & 76.6 & 128.7 \\
\hline $25-34$ & 73.7 & 161.1 & 37.3 & 34.4 & 71.7 & 36.3 & 53.0 & 89.4 \\
\hline $35-44$ & 66.8 & 113.0 & 29.5 & 14.7 & 44.2 & 37.3 & 31.4 & 68.8 \\
\hline $45-54$ & 69.7 & 114.9 & 16.7 & 13.8 & 30.5 & 53.0 & 86.7 & 84.5 \\
\hline $55-64$ & 35.4 & 56.0 & 7.9 & 1.0 & 8.8 & 27.5 & 19.6 & 47.2 \\
\hline TOTAL & 362.5 & 738.7 & 138.5 & 138.5 & 277.0 & 224.0 & 237.7 & 461.7 \\
\hline
\end{tabular}

TABLE 3: PREVALENCE OF PRESBYOPIA IN WARRI

\begin{tabular}{|c|c|c|c|c|c|c|}
\hline $\begin{array}{l}\text { AGE GROUP } \\
\text { (YRS) }\end{array}$ & \multicolumn{3}{|c|}{$\begin{array}{l}\text { NUMBER OF EYES WITH } \\
\text { PRESBYOPIA }\end{array}$} & \multicolumn{3}{|c|}{$\begin{array}{l}\text { PREVALENCE OF } \\
\text { PRESBYOPIA/1,000 }\end{array}$} \\
\hline $\begin{array}{r}6-14 \\
15-24 \\
25-34 \\
35-44 \\
45-54 \\
55-64 \\
\end{array}$ & $\begin{array}{l}21 \\
55 \\
69 \\
28 \\
\end{array}$ & $\begin{array}{l}14 \\
26 \\
42 \\
16 \\
\end{array}$ & $\begin{array}{r}35 \\
81 \\
111 \\
44 \\
\end{array}$ & $\begin{array}{l}20.6 \\
54.0 \\
67.8 \\
27.5 \\
\end{array}$ & $\begin{array}{l}13.8 \\
25.5 \\
41.3 \\
15.7 \\
\end{array}$ & $\begin{array}{c}34.4 \\
79.6 \\
109.0 \\
43.2 \\
\end{array}$ \\
\hline TOTAL & 173 & 98 & 271 & 169.9 & 96.3 & 266.2 \\
\hline
\end{tabular}

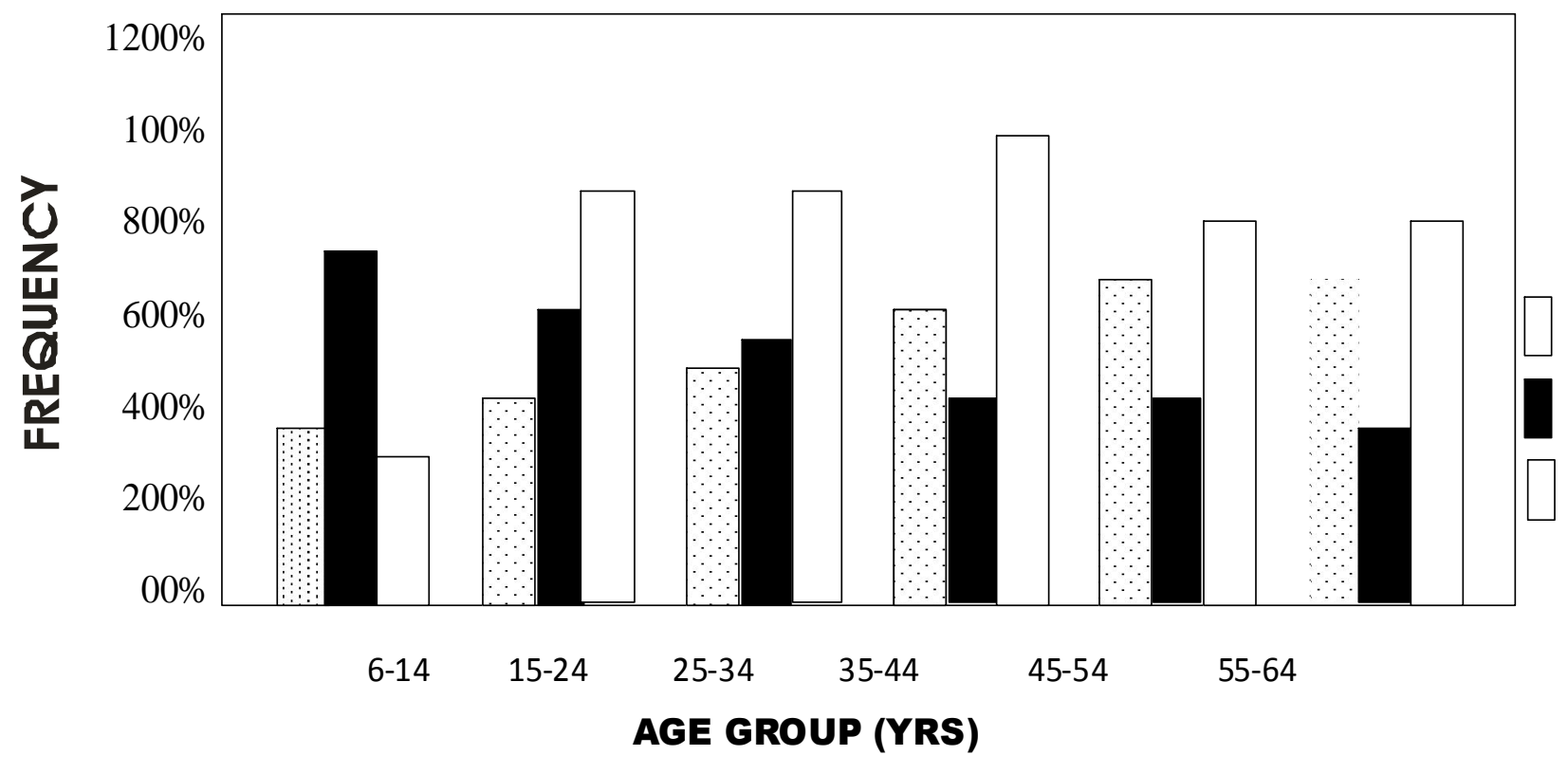

FIG. 1a: AGE FACTOR IN REFRACTIVE ERROR DISTRIBUTION 


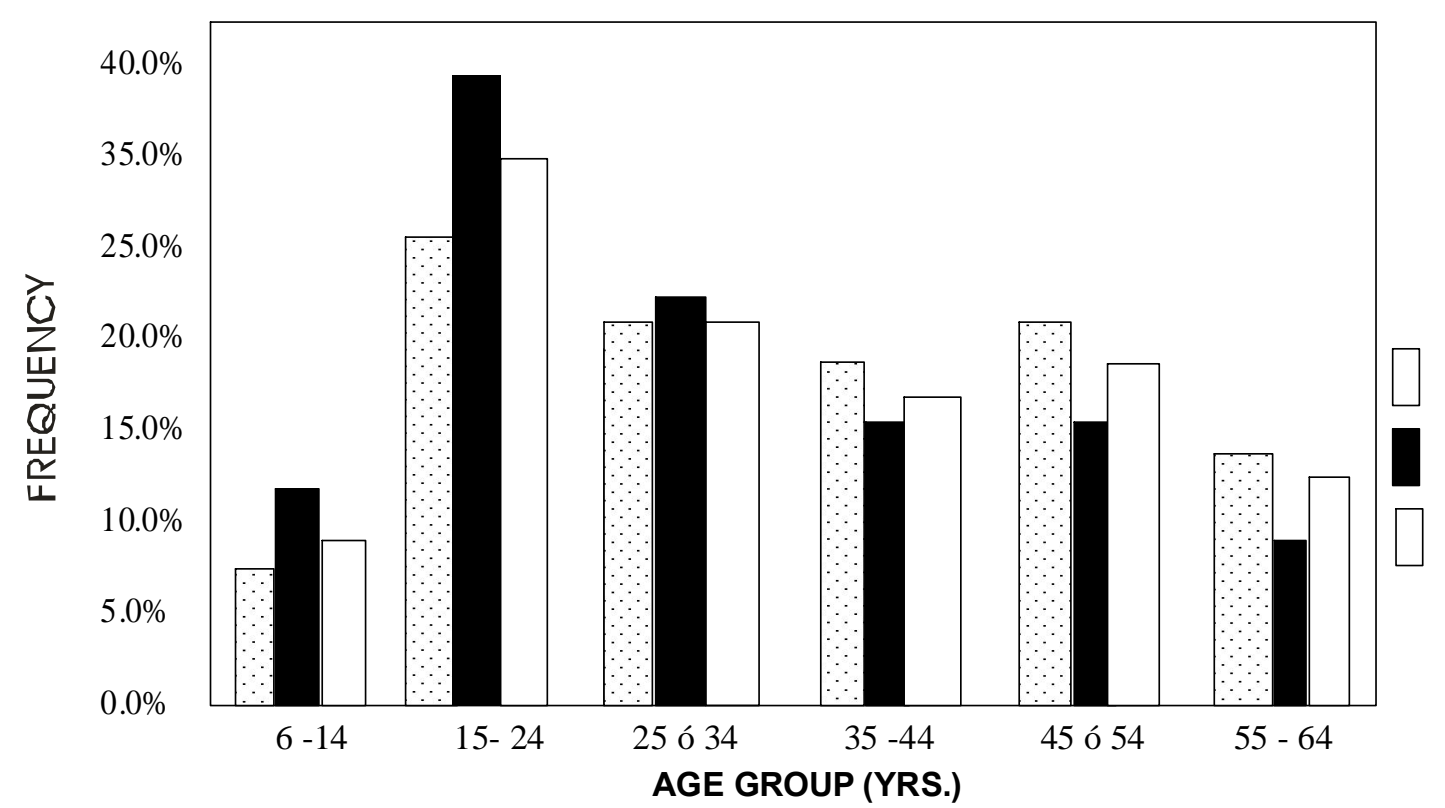

R.E. (MALE)

R.E. (FAMLE) R.E. (TOTAL)

FIGURE 1b: SEX FACTOR IN REFRACTIVE ERROR DISTRIBUTION

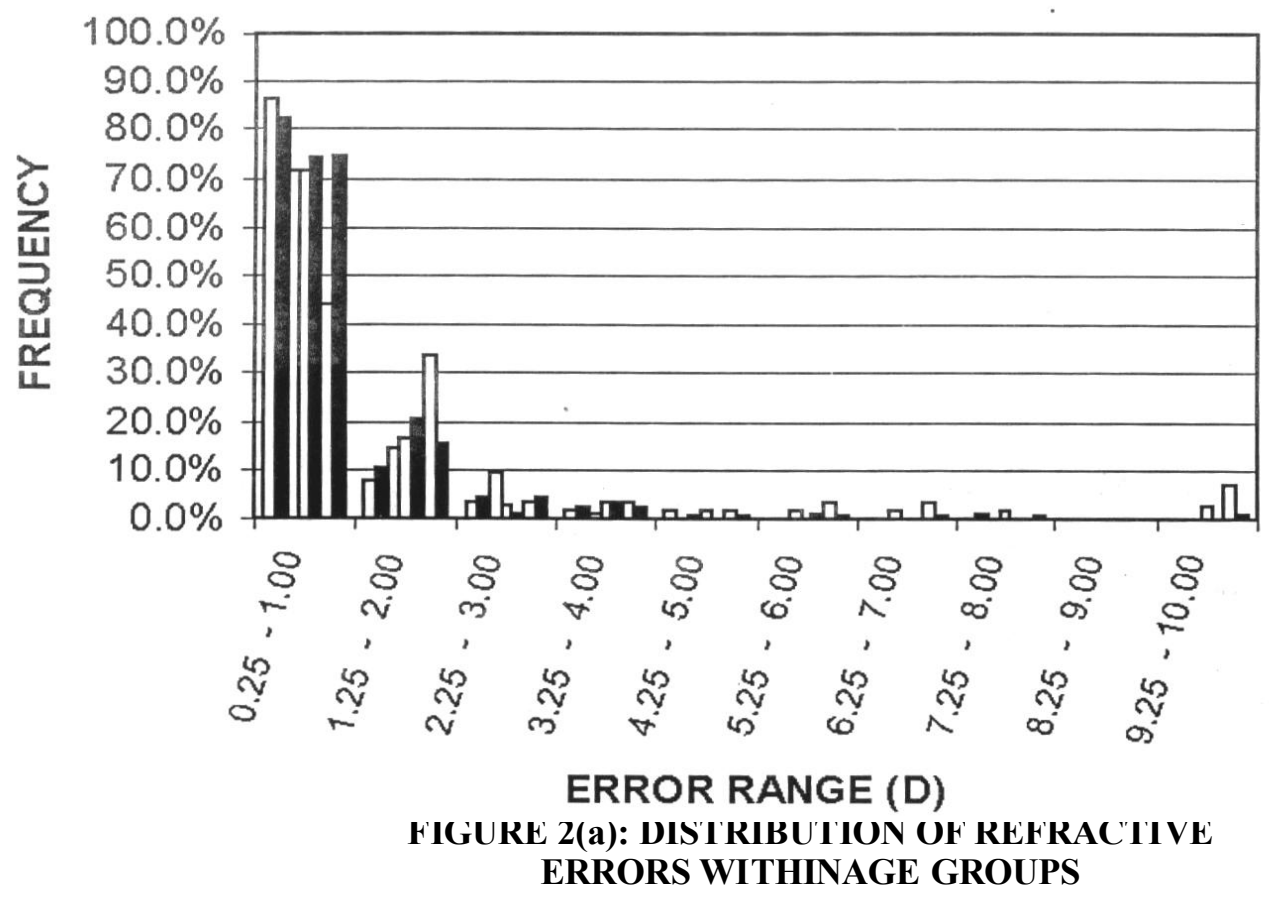

\begin{tabular}{|l|}
\hline$\square$ 6-14 YRS. \\
15-24 YRS. \\
$\square$ 25-34 YRS \\
$\square$ 35-44 YRS. \\
45-54 YRS. \\
$\square$ 55-64 YRS. \\
$\square$ TOTAL
\end{tabular}

2(a): DISTRIBUTION OF REFRACTIV ERRORS WITHINAGE GROUPS 


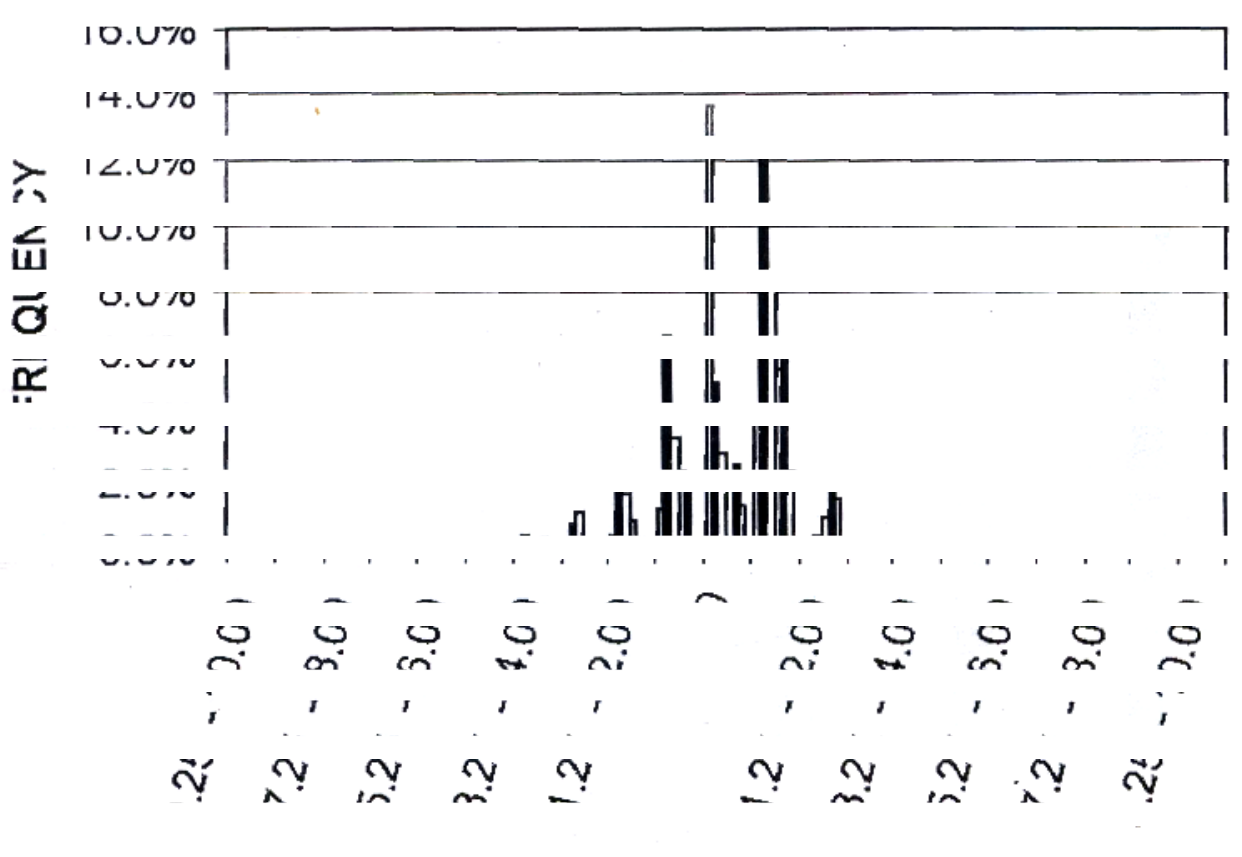

口6-14 YRS.

15-24 YRS.

$\square$ 25-34 YRS.

$\square$ 35-44 YRS.

45-54 YRS.

口55-64 YRS.

MYOPIA

HYPEROPIA

FIGURE 2(b): DISTRIBUTION OF REFRACTIVE POWERS ACROSS AGE GROUPS

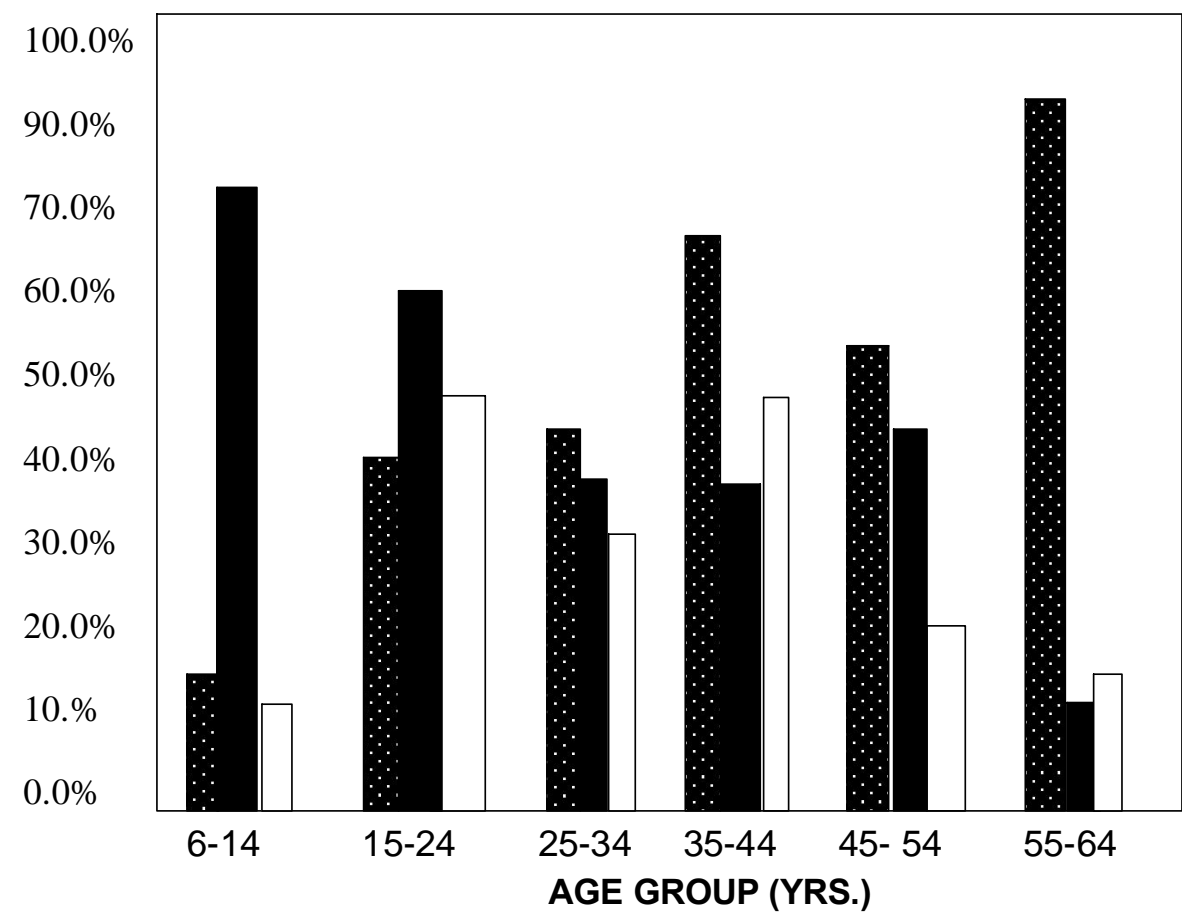

MYOPIA (MALE)

MYOPIA (FEMALE)

MYOPIA TOTAL

FIGURE 3(a): AGE GROUP FACTOR IN MYOPIA DISTRIBUTION 

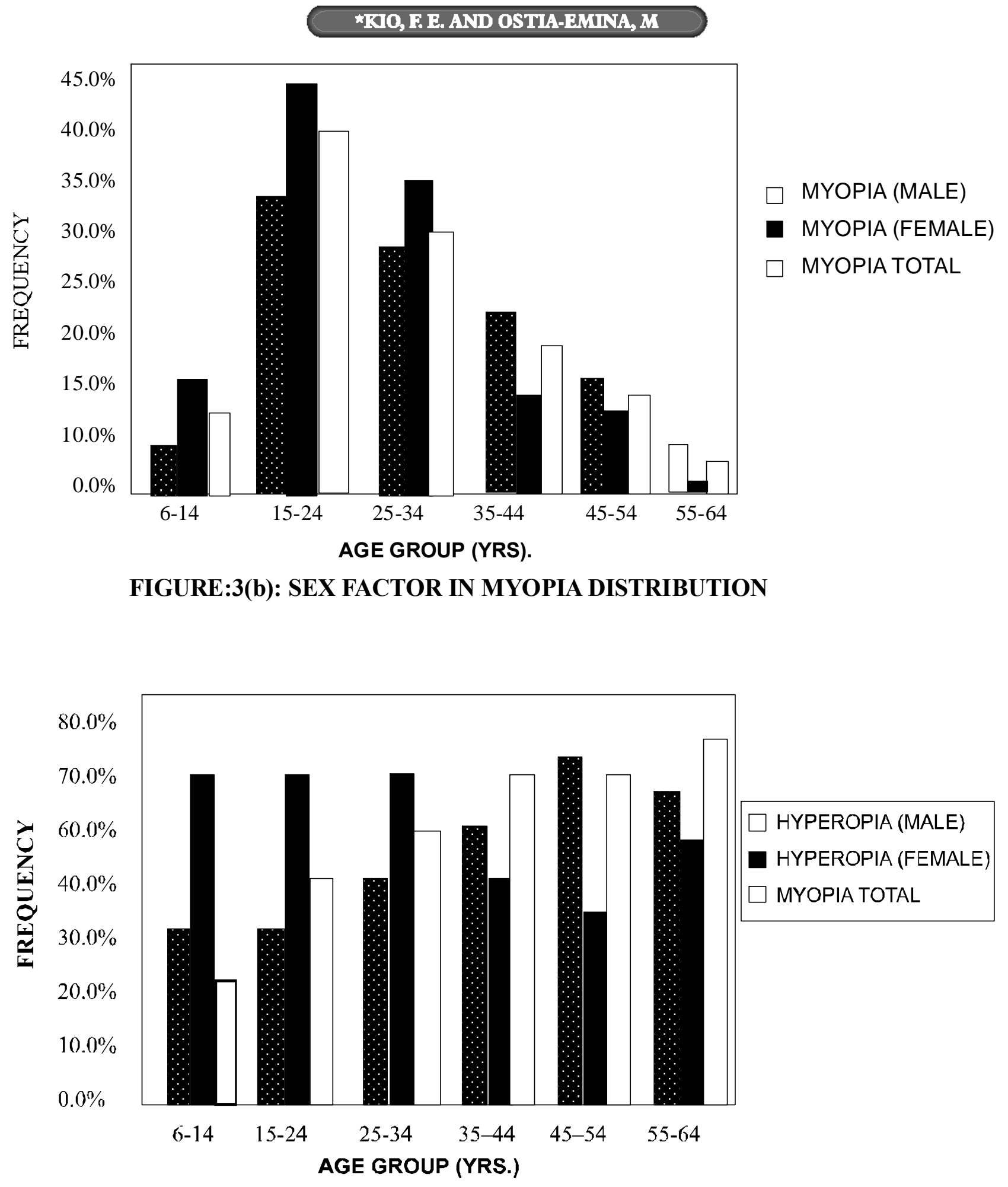

FIGURE 4(a): AGE GROUP FACTOR IN HYPEROPIA DISTRIBUTION 
